\title{
The Enlightenment of Marxist Freedom View on Ideological and Political Education in Colleges and Universities
}

\author{
Shuwei Wang \\ University of Electronic Science and Technology of China, Chengdu 610000, Sichuan, China \\ DOI: $10.32629 /$ jher.v2i6.579
}

Abstract: The pursuit of freedom by mankind has a long history. With the continuous and in-depth development of society, people have a deeper understanding of freedom. Freedom is the pursuit of a lifetime for everyone. In modern education, cultivating students to form a correct view on freedom to promote their free and comprehensive development has become one of the goals of education. Among the various ways to explore freedom, the Marxist freedom view is the most important and reasonable one.

Keywords: Marxism, freedom view, ideological and political education, college students

\section{The fundamental content and essence of Marxist freedom view}

"Freedom" is a very important part of Marxist theory. For the fundamental content and essence of Marxist freedom view, "Communist Manifesto", "German Ideology", "Manuscript of Economics and Philosophy in 1844" and other works have extremely detailed explanations made by Marx and Engels.

\subsection{The exposition of freedom in the Marxist humanistic view}

"All the characteristics of a species, the species characteristics lie in the nature of life activities, and the human characteristics are just free and conscious activities." [1] Therefore, in essence, human beings exist freely. On the one hand, freedom distinguishes humans from animals; on the other hand, freedom is the fundamental value that humans enjoy. Respecting a person means respecting his free nature. In the current new era, freedom is still our principle and pursuit of socialist construction.

In the process of the modernization of socialism with Chinese characteristics, the Communist Party of China has always adhered to the important position of "freedom", has always upheld the right of every citizen to pursue freedom, and has always advocated and led the entire society to pursue freedom. "Prosperity, democracy, civilization, harmony, freedom, equality, justice, rule of law, patriotism, dedication, integrity, and friendliness" ${ }^{[2]}$ is the 24-character socialist core values proposed to build social consensus and better develop socialism with Chinese characteristics in the 18th National Congress of the Communist Party of China, which are the code of conduct that every citizen should consciously practice. Among them, "freedom" is a requirement raised from the level of the entire society, and is the common value pursuit of the entire society. General Secretary has also repeatedly emphasized the importance of "freedom". He also emphasized in his speech at the celebration of the 100th anniversary of the founding of the Communist Party of China: "Promote the common values of peace, development, fairness, justice, democracy, and freedom for all mankind." [3]. The freedom here is different from the "liberalism" advocated by the western bourgeoisie. The freedom emphasized here refers to the ability to coordinate and maintain the normality of society, excluding the influence of negative factors such as individualism, selfish departmentalism, unprincipled nice-guyism, decentralism, and liberalism.

\subsection{Free and comprehensive development}

Marx and Engels said in the "Communist Manifesto": "Everyone's free and comprehensive development is the condition for the free development of all people." ${ }^{[4]}$ Free and comprehensive development has many meanings, and it not only refers to people's practical activities, Social relations also include the improvement of personal qualities, personalities, and abilities. There is a mutually reinforcing relationship between free development and comprehensive development. Individuals can obtain more sufficient free development space under the condition of realizing their own all-round development. In the same way, only after the individual breaks free from unnecessary restraints from the outside world can he strive for greater possibilities for his all-round development. Promoting the free and comprehensive development of people requires scientific ideological guidance, and the Marxist freedom view can provide this correct guidance. Therefore, in the process of advancing the development of socialism with Chinese characteristics, the Chinese Communists insist on applying the Marxist freedom view to all aspects of social development. Education is an important aspect of the practical application of the Marxist 
freedom view in China. In terms of education, China has always adhered to the goal of achieving the great rejuvenation of the Chinese nation, and has cultivated generations of outstanding socialist builders and successors by taking "cultivating free and fully developed people" as the specific way.

\subsection{Real people are the main body of freedom}

Marx and Engels especially emphasized "real people", believing that people are individuals in specific real life and have their own social relationships. They can participate in practical activities and constantly change according to different specific practices, and gradually develop and improve themselves in this process. From this perspective, the so-called "human freedom" actually has specific conditions, and this freedom will change with the different practical activities people participate in, the different social relations, and other specific conditions.

\subsection{Labor is the approach to achieving freedom}

Animals are directly in the same with their own life activities, and animals cannot distinguish themselves from their own life activities. ${ }^{[5]}$ But human beings are not that, human beings integrate their own consciousness into the activities of transforming the world, which presents a conscious and active form of practice, and fully proves that human beings are conscious beings. People can transform the world and create labor products in accordance with the "scale of any species" and "intrinsic scale" ${ }^{[6]}$. Products are of a human nature and can reflect people's thoughts and practices. In turn, people can reflect on their own thoughts embodied in these products, and reflect the improved results in the next practice. In this process, people are completely free and conscious.

\section{The main problems existing in the freedom view of contemporary college students}

\subsection{The arising of individualism}

The freedom emphasized by the Marxist freedom view and the freedom advocated by the entire society are conditional and relative freedom. However, some college students separate themselves from the collective when they understand "freedom", believing that individuals have absolute freedom, and individuals have absolute freedom that the state, society, and others cannot interfere with ${ }^{[7]}$. This kind of thoughts has gradually deepened, causing some distortions in the values of some college students, and gradually forming an extremely individualism style. These students separate their own personal interests, current interests from collective interests and long-term interests, emphasize personal values one-sidedly, and ignore cooperation and common values within the groups. This kind of one-sided understanding of "freedom" will gradually lead to a self-centered value orientation prevailing in campus, causing devastating consequences.

\subsection{Inadaptability to high degree of freedom}

Compared with the middle school years, college students have a higher degree of freedom. In terms of time, space, and psychology, college students have different disposable powers from the past, and this "thoughts of freedom" is gradually becoming stronger. However, when they break free from the shackles and gradually gain a greater degree of freedom, there will be confusion and panic that ensues. From the previous life controlled by teachers and parents, they are breaking away. On the one hand, they have gained more freedom to dominate; on the other hand, they have also lost the spiritual and actual care of the teachers and parents they once relied on. Some college students who have just broken away from the restrictions gain the "freedom" of not having to attend classes, but also lose the opportunity to learn. A higher degree of "freedom" means a higher degree of "self-responsibility", as well as a higher degree of uncertainty and openness. Many college students are not psychologically prepared while gaining this high degree of freedom, and do not have sufficient ability to utilize "freedom".

\section{Real difficulty faced by ideological and political education}

\subsection{Insufficient guidance of the main current values for students in colleges and universities}

The vigorous development of the Internet enables cultures from all over the world to flow freely and globally, which promotes cultural exchanges and also raises some issues of cultural penetration and cultural colonization. In addition, some bad social thoughts also spread through this platform. Young college students are just a passionate group with a noble pursuit of freedom. They are eager to be able to obtain information freely. The Internet platform just provides an opportunity. The quality of information in the Internet world is mixed, false accompanied, wrong-induced and the like. Some bad forces and organizations take this opportunity to carefully package the disseminated inferior information and transmit wrong values to young college students, leading to a challenge for colleges and universities to induce students to establish the right main current values. 


\subsection{The authority of information dissemination of education in colleges and universities has been impacted}

In the era of big data, the timeliness and interactivity of information dissemination and the ability of students to obtain information have been greatly enhanced, and the channels of information dissemination have become more diverse. Students can obtain the educational information they need through the Internet at any time, and can complete various links such as follow-up discussion, modification, and feedback through the Internet. The disseminator of educational information has become a broad Internet participant. Through the network to transmit education information to students, the "unidentified" network participants at the other end can easily influence the students' thoughts and behaviors, while universities have lost the opportunity in this battle for dominance in ideological and political education. The forced abandonment of colleges and universities in the discourse power of educational information has weakened their ability to control educational information and agenda setting, and the authority of colleges and universities for ideological and political education has been impacted.

3.3 The awareness and informatization level of big data in colleges and universities are insufficient

Nowadays, the period environment and the social development trend have fully demonstrated that it is a highly informatization age, and the study of students also depends to a large extent on various information such as the Internet and data. However, as for the current level of development of big data and informatization in universities, the most universities have problems such as insufficient professional talents, insufficient ideological and political education platforms, and low efficiency in data management and application.

\section{The enlightenment of Marxist freedom view on ideological and political education in colleges and universities}

General Secretary has repeatedly emphasized the need to use reasonable ideas to promote human liberation and free and comprehensive development. It just so happens that the Marxist freedom view is the "law of human liberation and free and comprehensive development" emphasized by the general secretary. It can lead us to find free ideas suitable for a socialist society with Chinese characteristics and avoid falling into the trap of Western liberalism. It can lead the ideological and political education in colleges and universities to creat a new chapter.

\subsection{Guide students to establish correct values}

First, when conducting ideological and political education, colleges and universities should affirm and respect students' correct pursuit of freedom and personality, support students to fully express their needs for freedom, help students solve the difficulties encountered in the pursuit of freedom, and guide them to fully consider Make rational decisions under the condition of consequences. Secondly, colleges and universities should guide students to pursue correct freedom and avoid students from embarking on the path of Western liberalism. On the one hand, colleges and universities should integrate the relevant content of the Marxist freedom view in the whole process of ideological and political education, and directly guide students to establish a correct view of freedom by setting up relevant courses; on the other hand, colleges and universities should be Incorporating the content of the Marxist concept of freedom in all aspects, so that students can be subtly influenced by correct ideas, so as to form correct personal values that can be adapted to the socialist ideas with Chinese characteristics.

\subsection{Create a good education environment}

"Prosperity, democracy, civilization, harmony; freedom, equality, justice, rule of law; patriotism, dedication, integrity, friendliness" [2], which is the core socialist values proposed by the 18th National Congress of the Communist Party of China. "Freedom" here is a profound manifestation of the combination of Marxist freedom view and the specific reality of Chinese social development, represents the common value pursuit of the entire society, and is a powerful ideological weapon for colleges and universities to create a good educational ecology. To create a good education ecology, on the one hand, colleges and universities must increase the integration of talent training, academic research, social services and other aspects with the core socialist values, and promote the formation of a common emotional value pursuit for teachers and students in the school. On the other hand, colleges and universities change their educational thinking, actively adapt to the network education environment, and improve their authority and affinity in network education. In the new era, college students are fully adapted to and enjoy the benefits of the Internet. The online life of students is rich and colorful. The ideological and political education of colleges and universities must combine the characteristics of the psychological acceptance of students in the new era, and create an education environment full of positive energy for students through new methods in the new era. 


\subsection{Establish a completed ideological and political education system}

On the one hand, colleges and universities should fully integrate their own resources in teaching, scientific research, culture, practice, and network. While guiding thinking and imparting knowledge to students, it should also focus on cultivating students' abilities. Concerning the fundamental task of establishing morality and cultivating people, cultivate outstanding socialist successors with lofty ideals and beliefs, sound personality, healthy physique, broad vision, and patriotism moral character. On the other hand, colleges and universities should establish an education concept of "whole development", cultivate outstanding students with whole development in morality, intelligence, physics, aesthetics, and labor, so that students can continuously improve and upgrade themselves in practice, and realize their own value in the process of serving the society and the country,

\section{References}

[1] (Germany) Marx, (Germany) Engels, compiled by the Compilation Bureau of Marx, Engels, Lenin and Stalin of the Central Committee of the Communist Party of China. The Complete Works of Marx and Engels, Vol. 42 [M]. Beijing: People's Publishing House, 2016.

[2] Xia Yun, Yan Xu. The cultural support for the great rejuvenation of the Chinese nation [M]. Guangzhou: Jinan University Press. 2018.

[3] Speech at the 100th Anniversary Meeting [J]. Seeking Truth, 2021(14).

[4] Compiled by the Compilation Bureau of Marx, Engels, Lenin and Stalin of the CPC Central Committee. Selected Works of Marx and Engels, Volume 1 [M]. Beijing: People's Publishing House, 2012.

[5] Marx. Manuscript of Economics and Philosophy in 1844 [M]. Beijing: People's Publishing House. 2014.

[6] Marx, compiled by the Compilation Bureau of Marx, Engels, Lenin and Stalin of the Central Committee of the Communist Party of China. Manuscript of Economics and Philosophy in 1844 [M]. Beijing: People's Publishing House, 2018.

[7] Ye Aihua. On the negative influence of neoliberalism on the values of college students and its countermeasures[J]. New West, 2019(12): 129+149. 